\title{
Proteinuria and the expression of the podocyte slit diaphragm protein, nephrin, in diabetic nephropathy: effects of angiotensin converting enzyme inhibition
}

\author{
R.G. Langham ${ }^{1}$, D.J. Kelly ${ }^{1}$, A. J. Cox ${ }^{1}$, N.M. Thomson ${ }^{2}$, H. Holthöfer ${ }^{3}$, P. Zaoui ${ }^{4}$, N. Pinel ${ }^{4}$, \\ D.J. Cordonnier ${ }^{4}$, R.E. Gilbert ${ }^{1}$ \\ ${ }^{1}$ University of Melbourne Department of Medicine, St. Vincent's Hospital, Fitzroy, Australia \\ ${ }^{2}$ Monash University Department of Medicine, Alfred Hospital, Prahran, Australia \\ 3 The Haartman Institute, Division of Bacteriology and Immunology, University of Helsinki, Finland \\ ${ }^{4}$ University Hospital Complex of Grenoble, France
}

\section{Abstract}

Aims/hypothesis. Proteinuria, reflecting increased glomerular permeability to macromolecules is a characteristic feature of diabetic nephropathy. Nephrin, a 1241-residue transmembrane protein is a key component of the podocyte slit pore membrane and a major contributor of the glomerular filtration barrier. We investigated the expression of nephrin in human kidney tissue from patients with diabetic nephropathy to elucidate its relationship with proteinuria and the effects of anti-proteinuric therapy with angiotensin converting enzyme inhibition.

Methods. Renal biopsies were examined from 14 patients with Type II (non-insulin-dependent) diabetes mellitus and proteinuria who had been randomised to receive treatment with the ACE inhibitor, perindopril (4 mg/day) or placebo for the preceding 2 years. These specimens were compared with control human tissue sections, obtained from areas of normal renal cortex following nephrectomy for malignancy. Proteinuria was measured, specimens were examined histologically for injury and the expression of nephrin messenger RNA was assessed by quantitative in situ hybridisation.

Results. Glomeruli from placebo-treated patients with diabetic nephropathy, showed a $62 \%$ reduction in nephrin expression compared with control subjects $(p=0.0003)$. In contrast, nephrin RNA in glomeruli from perindopril treated patients was similar to that in the non-diabetic control group. In both placebo and perindopril treated patients, a close inverse correlation was noted between the magnitude of nephrin gene expression and the degree of proteinuria (placebo: $r=0.86, p=0.013$, perindopril: $r=0.91, p=0.004)$.

Conclusion/interpretation. Modulation in nephrin expression is related to the extent of proteinuria in diabetic nephropathy. These changes define, at a molecular level alterations in the glomerulus that occur in relation to proteinuria in diabetes and the effects of anti-proteinuric treatment with ACE inhibition. [Diabetologia (2002) 45:1572-1576]

Keywords Nephrin, podocyte, proteinuria, diabetic nephropathy, angiotensin converting enzyme inhibition.
Diabetic nephropathy, like many renal diseases, is characterized by the early development of proteinuria followed by a later decline in glomerular filtration in association with glomerulosclerosis [1]. While consid-

Received: 8 April 2002 / Revised: 29 May 2002

Published online: 25 September 2002

(C) Springer-Verlag 2002

Corresponding author: R. E. Gilbert, MD, PhD, University of Melbourne Department of Medicine, St. Vincent's Hospital, 41 Victoria Parade, Fitzroy, Victoria, 3065, Australia.

E-mail: gilbert@ medstv.unimelb.edu.au erable advances have been made in understanding the mechanisms that lead to glomerulosclerosis [2, 3, 4], the pathogenesis of proteinuria is less well understood. Recently, the identification of mutations in the gene coding for the podocyte protein nephrin as the cause of the Finnish type of congenital nephrotic syndrome (NPHS1) [5], has provided substantial insight into the determinants of glomerular permeability. In addition to its established role in congenital nephrosis, animal studies have also implicated reduction in nephrin expression in acquired proteinuric renal diseases [6, 7]. We hypothesised that modulation in nephrin expres- 
sion can contribute to the pathogenesis of proteinuria in human diabetic nephropathy and the beneficial effects of ACE inhibition in reducing urinary protein excretion in this disorder [8]. To investigate this possibility we examined nephrin expression in patients who participated in the Diabiopsies trial, a prospective, biopsy-based study, examining the effects of the ACE inhibitor, perindopril, in patients with Type II (non-insulin-dependent) diabetes mellitus and nephropathy [9].

\section{Subjects and methods}

Renal tissue was obtained from biopsy specimens stored as part of the Diabiopsies study, the structural and functional aspects of which have been reported [9]. Biopsy tissue from 14 ( 7 perindopril, 7 placebo) of the 19 study patients examined at the end of the study (24 months) was available for analysis of gene expression. All patients gave their informed written consent. The study protocol was approved by the ethics committee (Comité Consulatif de Protection des Personnes dans la Recherche Biologique et Médicale) of Grenoble University Hospital. Control human tissue sections $(n=6)$ were obtained from normal renal cortex harvested from kidneys removed for renal malignancy. Tissue for analysis was sampled from the pole opposite the tumour. Glomerulosclerosis was assessed by examining all glomeruli in each biopsy section and grading them according to the severity of injury on a scale of 0 to 4 , as described [10]. Renal tissue obtained at the beginning of the study was not suitable for analysis of gene expression.

Quantitative in situ hybridization which permits the assessment of gene expression equivalent to northern blot analysis [11], was used to determine the magnitude of gene expression, as previously described for the analysis of gene expression in the kidney [12]. In brief, a 293 base pair cDNA coding for human nephrin was cloned into pGEM-T (Promega, Madison, Wis., USA), linearized with Not I and an antisense riboprobe was produced using T7 RNA polymerase. All tissue sections were processed in an identical manner and were hybridized in the same batch. Glomerular gene expression was assessed in emulsion-coated sections using computer-assisted image analysis (Analytical Imaging Station, Imaging Research, St. Catherine's, Ontario, Canada) to quantify autoradiographic grains $[13,14,15]$. Light microscopic images viewed through a $20 \times$ objective lens were captured and digitized using a Fujix HC-2000 digital camera (Fuji, Tokyo, Japan). Glomerular gene expression was then assessed by counting the number of autoradiographic grains in each glomerulus (average of five in each biopsy slide, mean 2-7) corrected for glomerular area $\left(\right.$ grains $/ \mu \mathrm{m}^{2}$ ). The magnitude of glomerular nephrin expression for each biopsy was then calculated by averaging the results obtained for all glomeruli within a single patient biopsy.
Because of a positively skewed distribution nephrin mRNA and proteinuria data were logarithmically transformed before statistical analysis. Data were analysed by ANOVA with correction for multiple comparisons using the Fisher's Least Significant Difference test. Linear regression analysis was used to determine the correlation between the magnitude of nephrin gene expression and proteinuria. Analyses were done using the Statview SE+ Graphics package (Abacus Concepts, Calabasas, Calif., USA). A $p$ value of less than 0.05 was considered statistically significant.

\section{Results}

As with the Diabiopsies study cohort, the subgroup from which the biopsies were available also showed no differences in blood pressure control, serum creatinine, creatinine clearance or glycated haemoglobin between perindopril and placebo treated groups either at baseline or over the period of the study (Table 1). Urinary protein excretion increased in the placebo group and decreased in the perindopril group over the trial period $(p=0.036)$. When compared with glomeruli from non-diabetic subjects, patients with diabetes had more extensive glomerulosclerosis. However, as previously reported for the entire study group, no difference between the perindopril treated group and the placebo group in the substudy (glomerulosclerosis index: $2.6 \pm 0.2$ vs $2.7 \pm 0.2$, placebo vs perindopril).

Emulsion-dipped biopsy sections of control tissue showed intense nephrin gene expression within the glomerulus (Fig. 1). Compared with control subjects, glomeruli from placebo-treated patients with diabetic nephropathy, showed a reduction in nephrin mRNA (Fig. 1, 2; $p=0.0003$ ). In contrast, nephrin gene expression in glomeruli from perindopril treated patients was similar to that from the non-diabetic control group (Fig. 1, 2; $p=0.003$ ). In both placebo and perindopril treated patients, a close inverse correlation was noted between the magnitude of nephrin gene expression and the degree of proteinuria (Fig. 3).

\section{Discussion}

The development of proteinuria is both a cardinal manifestation of glomerular injury and a pathogenetic factor in the progression of renal dysfunction [16]. Since the cloning of nephrin 3 years ago [5], and the

Table 1. Clinical parameters in study participants at study entry and at 2 years

\begin{tabular}{llc}
\hline Study parameter & Placebo $(n=7)$ & Perindopril $(n=7)$ \\
\hline Haemoglobin $\mathrm{A}_{1 \mathrm{C}}(\%)$ & $5.8 \pm 0.5 ; 7.2 \pm 0.6$ & $6.2 \pm 0.6 ; 7.8 \pm 0.6$ \\
Creatinine clearance $(\mathrm{ml} / \mathrm{min})$ & $124 \pm 24 ; 113 \pm 21$ & $126 \pm 10 ; 107 \pm 13$ \\
Mean arterial pressure $(\mathrm{mmHg})$ & $102 \pm 4 ; 106 \pm 4$ & $98 \pm 5 ; 95 \pm 4$ \\
Proteinuria (mg/day) & $278(112-687) ; 432(207-903)$ & $790(350-1787) ; 466(177-1224)^{\mathrm{a}}$ \\
\hline
\end{tabular}

${ }^{\mathrm{a}} p=0.036$

All data expressed as means \pm SEM except for protein excretion, expressed as geometric mean $(95 \%$ confidence intervals) 

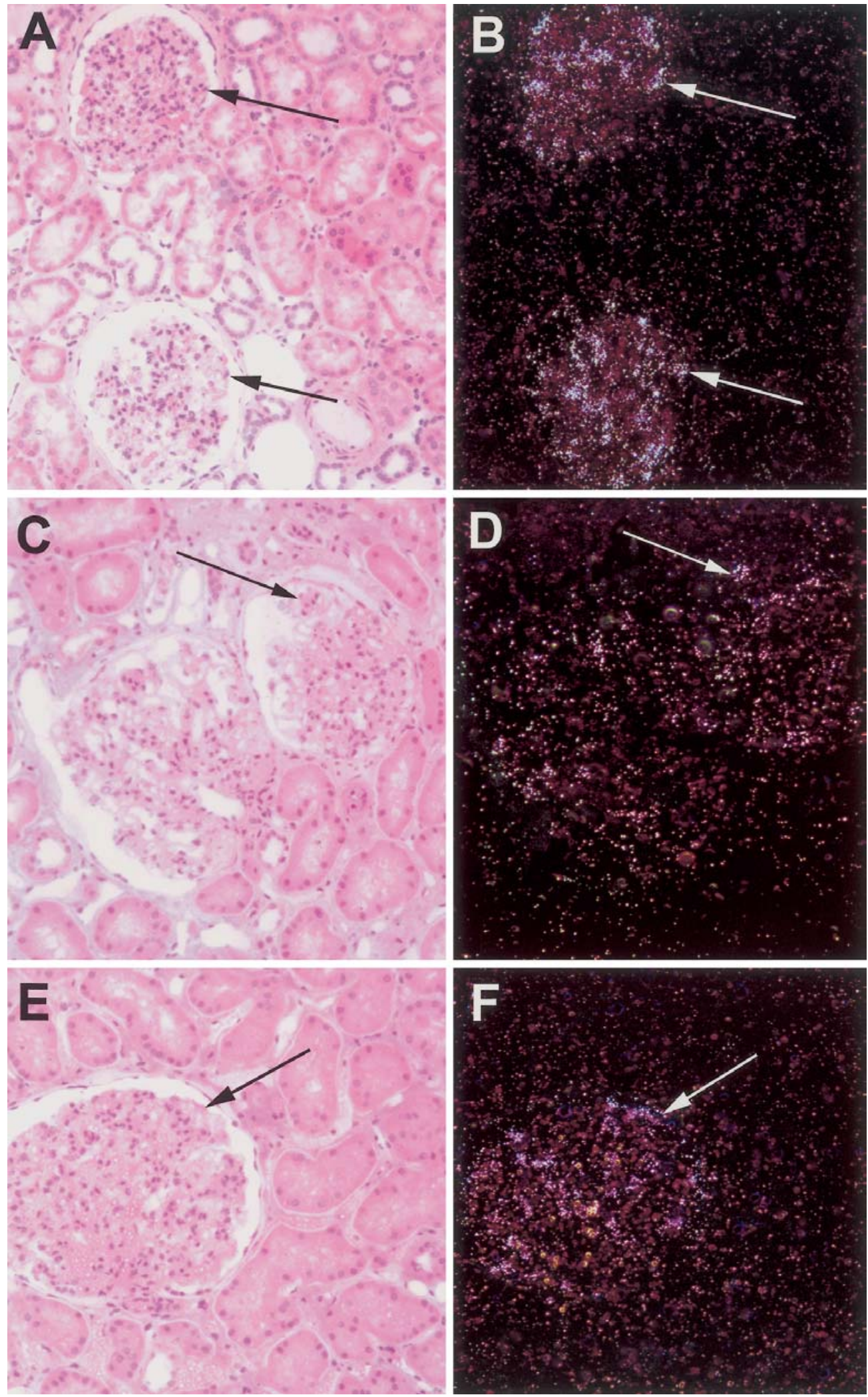

Fig. 1A-F. Representative bright (left panel) and dark field (right panel) in situ hybridization photomicrographs of nephrin gene expression in glomeruli from control subjects $(\mathbf{A}, \mathbf{B})$ and patients with diabetic nephropathy treated with placebo $(\mathbf{C}, \mathbf{D})$ or perindopril $(\mathbf{E}, \mathbf{F})$. Abundant transcript (bright spots on dark field image) was detected in glomeruli from the control subjects and perindopril-treated patients but not in biopsies form placebo treated patients with diabetic nephropathy. Magnification $\times 480$ 


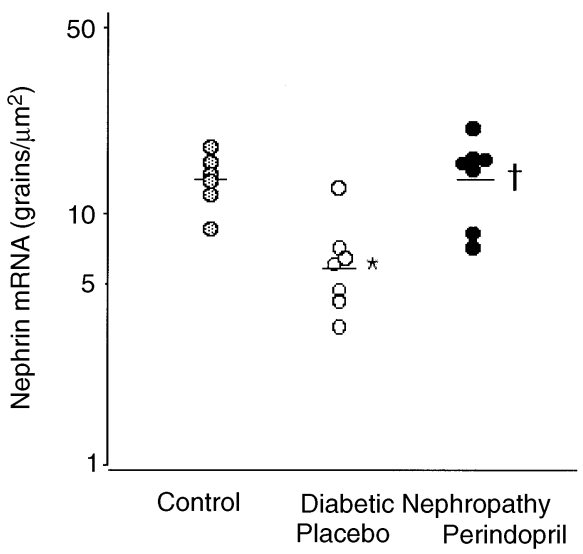

Fig. 2. Glomerular nephrin gene expression in control subjects $[12.9(10.5,16.1)]$ and in patients with diabetic nephropathy, receiving placebo $[6.05(4.4,9.6)]$ or perindopril treatment $[13.5(9.9,18.3)] . * p=0.0003$ vs control. $\dagger p=0.003$ versus placebo-treated diabetic patients

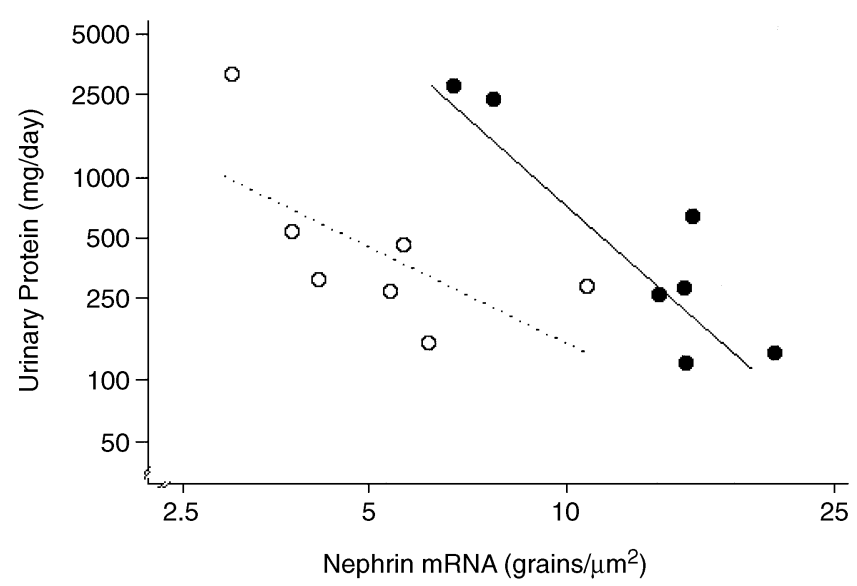

Fig. 3. Relation between nephrin gene expression and proteinuria in placebo $(\bigcirc)$ or perindopril treated patients $(0)$. A close inverse correlation between the magnitude of gene expression and the degree of proteinuria was noted in both placebo $(r=0.86, p=0.013)$ and in perindopril treated patients $(r=0.91$, $p=0.004)$

demonstration of its crucial role in the development and function of the glomerular filtration barrier [17], investigation into its potential role in the pathogenesis of acquired proteinuric diseases has been the subject of intensive research $[15,18,19]$. Our study shows several findings in relation to nephrin in diabetic nephropathy. Firstly, nephrin expression was reduced in glomeruli from patients with diabetic nephropathy. Secondly, renoprotective therapy with ACE inhibition, not only reduced urinary protein excretion but was also associated with increased nephrin expression when compared with placebo-treated patients. Thirdly, a close correlation between the magnitude of nephrin gene expression and the degree of proteinuria was observed in both placebo and in perindopril-treated diabetic patients.
The renoprotective and anti-proteinuric effects of agents that block the renin-angiotensin system are well established. Indeed, the anti-proteinuric effects of ACE inhibitors and angiotensin receptor blockers are viewed as an important factor in their renoprotective effects in both diabetic and non-diabetic kidney disease [16, 20, $21,22,23]$. However, the mechanisms underlying the anti-proteinuric effects of blockade of the RAS are not understood completely. Angiotensin II has long been known to regulate glomerular function by modulation of arteriolar tone and ultrafiltration co-efficient $K_{\mathrm{f}}$ $[24,25]$ with cognate receptors present on vascular smooth muscle, mesangial and capillary endothelial cells [26]. Recently, functioning receptors for angiotensin II have also been identified in the podocyte, both in culture [27], and in freshly isolated intact glomeruli [28].

In addition to reducing proteinuria, we also found that ACE inhibitor treatment, was associated with nephrin expression of similar magnitude to that in non-diabetic control subjects. Previous studies [29], based on work in animal experiments and theoretical modelling, have suggested that ACE inhibition attenuates urinary protein excretion by reducing the radius of hypothetical membrane pores. Our results are consistent with these findings and the role of nephrin in pore structure [17], providing a molecular component to our understanding of the pathophysiological processes that underlie the development of proteinuria in diabetic nephropathy and the anti-proteinuric effects of ACE inhibition. Although our results suggest that modulation in nephrin expression is an important determinant of proteinuria, other mechanisms are also likely to contribute. These include changes in glomerular basement membrane composition [30], hemodynamic factors [25] and even the absorptive functions of the proximal tubule [31].

Since nephrin is a podocyte specific protein, it is possible that reduction in its expression reflects podocyte loss in diabetes. Podocyte loss could be common to a range of renal diseases, implicated in both the pathogenesis of progressive glomerular injury and in the development of proteinuria [32]. Although podocyte loss is feature of diabetes, it occurs very early in the disease and thereafter remains relatively constant [33]. Thus, the early podocyte loss in diabetes and the inability of this highly differentiated cell to replicate [34], suggest the increased nephrin expression in perindopril-treated patients cannot be explained by an ACE inhibitor-induced increase in podocyte number.

In summary, the reduction in nephrin expression could be a determinant of glomerular hyperpermeability in diabetic nephropathy and attenuation of these changes with ACE inhibition could contribute to the anti-proteinuric effects of this class of drug. 
Acknowledgements. This work was supported in part by grants from the National Health and Medical Research Council of Australia, Juvenile Diabetes Research Foundation International (JDRFI) and the Royal Australasian College of Physicians Pfizer Medical Research Fellowship. R.E. Gilbert is a recipient of a career development award and D.J. Kelly is a recipient of a post doctoral fellowship, both from JDRFI. The authors are indebted to the Diabiopsies Investigators for providing the renal biopsy material.

\section{References}

1. Mogensen CE, Schmitz O (1988) The diabetic kidney: from hyperfiltration and microalbuminuria to end-stage renal failure. Med Clin North Am 72: 1465-1492

2. Border WA, Yamamoto T, Noble NA (1996) Transforming growth factor- $\beta$ in diabetic nephropathy. Diabetes Metab Rev 12: 309-339

3. Striker GE, Eastman RD, Striker LJ (1996) Diabetic nephropathy - molecular analysis of extracellular matrix and clinical studies update. Nephrol Dial Transplant 11: 58-61

4. McLennan SV, Fisher EJ, Yue DK, Turtle JR (1994) High glucose concentration causes a decrease in mesangium degradation. Diabetes 43: 1041-1045

5. Kestila M, Lenkkeri U, Mannikko M et al. (1998) Positionally cloned gene for a novel glomerular protein - nephrin - is mutated in congenital nephrotic syndrome. Mol Cell 1:575-582

6. Benigni A, Tomasoni S, Gagliardini E et al. (2001) Blocking angiotensin II synthesis/activity preserves glomerular nephrin in rats with severe nephrosis. J Am Soc Nephrol 12: $941-948$

7. Bonnet F, Cooper ME, Kawachi H, Allen TJ, Boner G, Cao Z (2001) Irbesartan normalises the deficiency in glomerular nephrin expression in a model of diabetes and hypertension. Diabetologia 44: 874-877

8. Kasiske B, Kalil R, Ma J, Liao M, Keane W (1993) Effect of antihypertensive therapy on the kidney in patients with diabetes: a meta-regression analysis. Ann Intern Med 118:129-138

9. Cordonnier DJ, Pinel N, Barro C et al. (1999) Expansion of cortical interstitium is limited by converting enzyme inhibition in type 2 diabetic patients with glomerulosclerosis. J Am Soc Nephrol 10: 1253-1263

10. Scholey JW, Miller PL, Rennke HG, Meyer TW (1989) Effect of converting enzyme inhibition on the course of adriamycin-induced nephropathy. Kidney Int 36: 816-822

11. Jonker A, Boer PA de, Hoff MJ van den, Lamers WH, Moorman AF (1997) Towards quantitative in situ hybridization. J Histochem Cytochem 45: 413-423

12. Kelly DJ, Gilbert RE, Cox AJ, Soulis T, Jerums G, Cooper ME (2001) Aminoguanidine ameliorates overexpression of prosclerotic growth factors and collagen deposition in experimental diabetic nephropathy. J Am Soc Nephrol 12: 2098-2107

13. Baskin DG, Stahl W (1993) Fundamentals of quantitative autoradiography by computer densitometry for in situ hybridization with emphasis on ${ }^{33} \mathrm{P}$. J Histochem Cytochem 41: $1767-1773$

14. Mulder H, Ahrén B, Sundler F (1996) Applications of in situ hybridization and immunocytochemistry for localization and quantification of gene expression-A lesson from islet amyloid peptide. In: Gu J (ed) Analytical morphologytheory, applications and protocols. Eaton Publishing, Natick, pp 115-137

15. Patrakka J, Ruotsalainen V, Ketola I et al. (2001) Expression of nephrin in pediatric kidney diseases. J Am Soc Nephrol 12: 289-296
16. Remuzzi G, Bertani T (1998) Pathophysiology of progressive nephropathies. N Engl J Med 339: 1448-1456

17. Tryggvason K (1999) Unraveling the mechanisms of glomerular ultrafiltration: nephrin, a key component of the slit diaphragm. J Am Soc Nephrol 10: 2440-2445

18. Doublier S, Ruotsalainen V, Salvidio G et al. (2001) Nephrin redistribution on podocytes is a potential mechanism for proteinuria in patients with primary acquired nephrotic syndrome. Am J Pathol 158: 1723-1731

19. Furness PN, Hall LL, Shaw JA, Pringle JH (1999) Glomerular expression of nephrin is decreased in acquired human nephrotic syndrome. Nephrol Dial Transplant 14: 12341237

20. Lewis EJ, Hunsicker LG, Bain RP, Rohde RD, for the Collaborative Study Group (1993) The effect of angiotensin-converting-enzyme inhibition on diabetic nephropathy. N Engl J Med 329: 1456-1462

21. The GISEN Group (Gruppo Italiano di Studi Epidemiologici in Nefrologia) (1997) Randomised placebo-controlled trial of effect of ramipril on decline in glomerular filtration rate and risk of terminal renal failure in proteinuric, non-diabetic nephropathy. Lancet 349: 1857-1863

22. Lewis EJ, Hunsicker LG, Clarke WR et al. (2001) Renoprotective effect of the angiotensin-receptor antagonist irbesartan in patients with nephropathy due to type 2 diabetes. N Engl J Med 345: 851-860

23. Brenner BM, Cooper ME, Zeeuw D de et al. (2001) Effects of losartan on renal and cardiovascular outcomes in patients with type 2 diabetes and nephropathy. N Engl J Med 345: 861-869

24. Ichikawi I, Harris RC (1991) Angiotensin actions in the kidney: renewed insight into the old hormone. Kidney Int 40: 583-596

25. Johnston CI, Risvanis J, Naitoh M, Tikkanen I (1998) Mechanism of Progression of renal disease - current hemodynamic concepts. J Hypertens 16: S3-S7

26. Inagami $T$ (1999) Molecular biology and signaling of angiotensin receptors: an overview. J Am Soc Nephrol 10 [Suppl 11]: S2-S7

27. Sharma M, Sharma R, Greene AS, McCarthy ET, Savin VJ (1998) Documentation of angiotensin II receptors in glomerular epithelial cells. Am J Physiol 274: F623-F627

28. Gloy J, Henger A, Fischer KG et al. (1998) Angiotensin II modulates cellular functions of podocytes. Kidney Int 54: S168-S170

29. Remuzzi A, Puntorieri S, Battaglia C, Bertani T, Remuzzi G (1990) Angiotensin converting enzyme inhibition ameliorates glomerular filtration of macromolecules and water and lessens glomerular injury in the rat. J Clin Invest 85: $541-549$

30. Born J van den, Gunnarsson K, Bakker MA et al. (1995) Presence of $\mathrm{N}$-unsubstituted glucosamine units in native heparan sulfate revealed by a monoclonal antibody. J Biol Chem 270: 31303-31309

31. Russo LM, Bakris GL, Comper WD (2002) Renal handling of albumin: a critical review of basic concepts and perspective. Am J Kidney Dis 39: 899-919

32. Rennke HG (1994) How does glomerular epithelial cell injury contribute to progressive glomerular damage? Kidney Int [Suppl] 45: S58-S63

33. Steffes MW, Schmidt D, McCrery R, Basgen JM, Group ID (2001) Glomerular cell number in normal subjects and in type 1 diabetic patients. Kidney Int 59: 2104-2113

34. Kriz W (1996) Progressive renal failure - inability of podocytes to replicate and the consequences for development of glomerulosclerosis. Nephrol Dial Transplant 11: 17381742 